\title{
ORIGINAL ARTICLE \\ Gainful employment and risk of mortality after spinal cord injury: effects beyond that of demographic, injury and socioeconomic factors
}

\author{
JS Krause, LL Saunders and J Acuna
}

\begin{abstract}
Objective: To evaluate the association of three levels of gainful employment with the risk of mortality after traumatic spinal cord injury (SCl) while controlling for known predictors of mortality status (including education and income).

Study design: Prospective cohort study

Setting: A total of 20 federally funded SCI Model Systems of care in the United States.

Methods: Participants included 7955 adults with traumatic SCI. Preliminary assessments were conducted between 1995 and 2006. Mortality status was determined by the Social Security Death Index (1308 deaths). A two-stage logistic regression model was used to estimate the chance of dying in any given year. Life expectancy was calculated under different economic assumptions.

Results: Compared with those who were working $30+\mathrm{h}$ per week, the odds of mortality was 1.37 for those who worked $1-29 \mathrm{~h}$ and 1.67 for those who were unemployed. The addition of gainful employment only modestly reduced the effects of household income and education, both of which remained significant. For instance, the odds of mortality for household income (referent $\$ 75000+$ ) decreased from 1.50 to 1.38 for $\$ 25000-\$ 75000$ and from 2.10 to 1.82 for $<\$ 25000$. Life expectancy varied widely depending on socioeconomic characteristics more than doubling under certain assumptions.

Conclusion: Substantial variation in mortality is attributable to employment, above and beyond the effects of previously established demographic, injury and socioeconomic predictors. Although some excess mortality may be the inevitable consequence of SCl, risk is substantially increased with poor socioeconomic characteristics.
\end{abstract}

Spinal Cord (2012) 50, 784-788; doi:10.1038/sc.2012.49; published online 1 May 2012

Keywords: spinal cord injury; mortality; employment; economics; income; life expectancy

\section{INTRODUCTION}

Spinal cord injury (SCI) is related to an elevated risk of mortality, the extent of which depends on the location of the lesion and neurological completeness of injury. ${ }^{1}$ Because mortality rates among first-year survivors have remained essentially unchanged since the $1980 \mathrm{~s}^{1,2}$ excess mortality is typically viewed as an inevitable consequence of SCI. However, research on factors other than demographics suggests that socioeconomic conditions may have a profound effect on risk of mortality, both in the general population and after SCI. ${ }^{3-5}$ This research has typically focused on education and income to the exclusion of gainful employment as a risk factor for mortality.

Three previous analyses of data from the SCI Model Systems (SCIMSs) in the United States indicated significant relationships between socioeconomic indicators and risk of mortality after SCI. ${ }^{6-8}$ In the first study, economic status was measured using the economic self-sufficiency score of the Craig Handicap Assessment and Reporting Technique, which has a relatively low ceiling of 1.5 times the poverty level, along with the type of insurance and several other predictors including health status. ${ }^{6}$ Both the economic self-sufficiency score and insurance were significantly related to both the probability of mortality and life expectancy. This study was replicated with smaller observed effects, largely due to a nonsignificant relationship between type of insurance and mortality. ${ }^{7}$ More recently, the effects of education and household income were isolated while controlling for demographic and injury characteristics. ${ }^{8}$ Compared with those with household income in excess of $\$ 75000$, those with annual household income of $<\$ 25000$ had a 2.31 greater odds of mortality, and those whose income was between $\$ 25000$ and $\$ 74999$ had a 1.61 greater odds of mortality. These findings were similar to those in an independent study using a smaller participant sample. ${ }^{9}$

These studies demonstrated the importance of income and education but did not address gainful employment. Studies in the general population have rarely addressed employment, ${ }^{3-5}$ as employment is fundamental to adult life and employment rates are typically high. However, given the low employment rates and the relationship of poor employment outcomes with policy factors (particularly work disincentives in the USA), employment may be a critical, yet overlooked, risk factor for mortality. A relationship between employment and mortality would suggest that risk of mortality may be decreased by policy or programmatic changes improving employment outcomes. 


\section{Purpose}

Our purpose was to identify the association of three indicators of socioeconomic status (SES) with risk of mortality and differential life expectancy using data from the SCIMSs in the United States. The unique contribution of this study was the demonstration of the relationship of three levels of employment (unemployed, 1-29 h and $\geqslant 30 \mathrm{~h}$ per week) with the risk of mortality while systematically building upon more limited analysis of established SES indicators (education and income). Therefore, we were able to isolate the relationship of employment with the risk of mortality above and beyond the effects of other aspects of SES to help determine the extent to which excess mortality is indeed an inevitable consequence of SCI.

\section{Hypotheses}

1. Employment status is significantly predictive of mortality after controlling for known risk factors.

2. There is a decreasing risk of mortality as a function of the three levels of employment, with the lowest risk among those working the greatest number of hours.

3. Education and household income will also be significantly related to risk of mortality.

\section{MATERIALS AND METHODS}

\section{Participants}

After obtaining the approval of the institutional review board, participants were recruited during acute care or inpatient rehabilitation at 1 out of 20 SCIMS hospitals. Eligibility criteria included: traumatic SCI, admission within 1 year of injury, discharged alive with some residual neurological deficit, minimum of 18 years of age, non-ventilator-dependent and having data on household income and employment collected at least once post discharge. The sample was comprised of 7955 participants from the previously reported study by Krause et al. ${ }^{8}$ (72 persons missing work hours were excluded).

\section{Procedures}

The National Spinal Cord Injury Statistical Center contains data reported from SCIMS rehabilitation hospitals. Data were collected during inpatient rehabilitation and at discharge, 1 year post injury, 5 years post injury and at 5-year intervals thereafter through an in-person, telephone or mailed interview. Allcause mortality was assessed annually using the Social Security Death Index, an on-line mortality database, with the most recent searches conducted in February and March 2011. The Security Death Index has 94.2\% sensitivity and $99.5 \%$ specificity in identifying mortality among persons in the National
Spinal Cord Injury Statistical Center database. ${ }^{10}$ Participants who were not found deceased were presumed to be alive and their censoring date was either the most recent date of contact or 1 January 2011.

\section{Measures}

Form I data are collected during inpatient rehabilitation, and Form II is data collected at follow-up. Several demographic and injury characteristics were taken from the Form I. Injury level was categorized as cervical 1-4 (C1-C4), cervical 5-8 (C5-C8) and non-cervical, whereas injury completeness was measured by either Frankel grade (the Frankel system was used until 1993) ${ }^{11}$ or the American Spinal Injury Association Impairment Scale (AIS). ${ }^{12}$ Each Frankel grade was grouped with the corresponding AIS grade. Other variables were sex, race, current age, calendar year and years since injury. Cause of injury was grouped as: (a) violent, (b) motor vehicle crash/fall/sports/ unknown etiology and (c) other. ${ }^{8}$

Annual household income was categorized as: (a) \$0-\$24 999, (b) \$25000$\$ 74999$ and $(c) \geqslant \$ 75000$. The number of hours working in paid employment was categorized, consistent with previous SCI research, ${ }^{13}$ as: (a) unemployed, (b) $1-29 \mathrm{~h}$ and (c) $\geqslant 30 \mathrm{~h}$. Education was categorized as: (a) less than a high school certificate, (b) high school certificate/associate's degree and (c) bachelor's degree or more.

\section{Analysis}

We used logistic regression analysis with person-years. ${ }^{6-8}$ Each person contributed one observation for each year of follow-up, beginning with the first instance of SES data collection post injury. The outcome was survival to the end of the year or death. This method produces results similar to a Cox proportional hazards model but more easily distinguishes the effects of current age, time post injury and calendar year. ${ }^{14}$ Collinearity was assessed by examination of correlation coefficients among risk factors (no problems were detected).

Interaction terms were tested in the multivariable model, between the primary independent variable (work hours) and all the other independent variables and between SCI level and AIS/Frankel grade. There were no significant interactions with work hours, but the interaction between SCI level and AIS/Frankel grade was significant. ${ }^{8}$ A two-stage regression analysis was conducted, with work hours added in stage 2 . This allowed us to isolate the association of work hours with mortality while evaluating changes in the strength of the association of income and education with mortality. HosmerLemeshow and global $\chi^{2}$-tests were used to assess goodness-of-fit. ${ }^{15}$ The C-statistic, measuring area under the receiver operating characteristic curve, was used to assess discriminatory ability. ${ }^{15}$

Life expectancy estimates were calculated using methods and examples from the Krause et al., ${ }^{6}$ Strauss et al., ${ }^{7}$ and Krause et al. ${ }^{8}$ studies. The calculation identifies the probability of survival each year through age 100. Example life expectancies were generated using the hypothetical case of a white male, motor

Table 1 Percentage of persons by household income, education level and hours worked (total numbers and percentages are displayed)

\begin{tabular}{|c|c|c|c|c|c|c|c|c|c|c|}
\hline & \multicolumn{3}{|c|}{ Low } & \multicolumn{3}{|c|}{ Middle } & \multicolumn{3}{|c|}{ High } & \\
\hline & \multirow[b]{2}{*}{$<12$} & \multirow[b]{2}{*}{$12-15$} & \multirow[b]{2}{*}{$16+$} & \multicolumn{3}{|c|}{ Education ${ }^{\mathrm{b}}$} & \multirow[b]{2}{*}{$<12$} & \multirow[b]{2}{*}{$12-15$} & \multirow[b]{2}{*}{$16+$} & \\
\hline & & & & $<12$ & $12-15$ & $16+$ & & & & \\
\hline 0 & 968 (12.2) & $2233(28.1)$ & $318(4.0)$ & $198(2.5)$ & 1245 (15.7) & $317(4.0)$ & $17(0.2)$ & $241(3.0)$ & $193(2.4)$ & $5730(72.0)$ \\
\hline $1-29$ & $17(0.2)$ & $153(1.9)$ & $58(0.7)$ & $9(0.1)$ & $115(1.4)$ & $81(1.0)$ & $4(0.1)$ & $44(0.6)$ & $50(0.6)$ & $531(6.7)$ \\
\hline$>30$ & $33(0.4)$ & $163(2.0)$ & $63(0.8)$ & $20(0.3)$ & $453(5.7)$ & 419 (5.3) & $4(0.1)$ & $185(2.3)$ & $354(4.5)$ & 1694 (21.3) \\
\hline Totals (education) & $1018(12.8)$ & 2549 (32.0) & $439(5.5)$ & $227(2.9)$ & $1813(22.8)$ & 817 (10.3) & $25(0.3)$ & $470(5.9)$ & $597(7.5)$ & \\
\hline Totals (income) & $4006(50.4)$ & & & 2857 (35.9) & & & 092 (13.7) & & & \\
\hline
\end{tabular}

a For income, low $=<\$ 25000$, middle $=\$ 25000-74999$ and high $=\$ 75000+$.

bor education, $<12=<$ high school, $12-15=$ high school/associates and $16+=$ bachelors + . 
vehicle crash etiology, AIS A injury. We calculated estimates varying current age (25 and 50) and neurological injury level (C1-C4 and non-cervical), as well as each of the three SES indicators. We assumed that each variable was consistent throughout the lifespan, with the exception of hours per week employed for which the assumption was made through age 64 , after which the assumption was 0 .

\section{Statement of ethics}

We certify that all the applicable institutional and governmental regulations concerning the ethical use of human volunteers were followed during the course of this research.

\section{RESULTS}

There were 1308 deaths and 70336 person-years of follow-up. The time between injury date and study enrollment was $8.2 \pm 8.1$ years. In all, $79.4 \%$ were male, $72.3 \%$ were white and $50.4 \%$ had a cervical injury. Overall, $50.4 \%$ of participants reported an annual household income of $<\$ 25000$ and $16.0 \%$ reported having less than a high school certificate (Table 1). Additionally, $72.0 \%$ were unemployed. The majority of participants were in the lowest income and workhour groups $(44.3 \%)$. Only $6.9 \%$ of participants reported having worked $\geqslant 30 \mathrm{~h}$ per week and annual income of $\geqslant \$ 75000$. There were modest intercorrelations between the three socioeconomic indicators ranging from 0.36-0.40 using Spearman's Rho.

\section{Regression analysis}

In stage 1 , all the variables were statistically significant, except for etiology (Table 2). Compared with those with a 4 -year degree, those with a high school certificate/associate's degree had 1.40 greater odds of mortality (95\% confidence interval $(\mathrm{CI})=1.19-1.64$ ), and those without a high school certificate had 1.68 greater odds of mortality (95\% CI $=1.37-2.06)$. Compared with those who reported higher

Table 2 Adjusted odds ratios (ORs) and 95\% confidence intervals (Cls) for mortality

\begin{tabular}{|c|c|c|c|}
\hline Characteristic & Krause et al. modela $(95 \% \mathrm{Cl}$ ) & Stage I (95\% Cl) & Stage // $(95 \%$ Cl) \\
\hline \multicolumn{4}{|l|}{ Demographic factors } \\
\hline \multicolumn{4}{|l|}{ Sex (vs female) } \\
\hline Male & $1.24(1.05-1.46)$ & $1.30(1.12-1.51)$ & $1.32(1.14-1.53)$ \\
\hline \multicolumn{4}{|l|}{ Race (vs other) } \\
\hline White & $1.32(1.00-1.74)$ & $1.43(1.14-1.79)$ & $1.45(1.16-1.82)$ \\
\hline Black & $1.45(1.24-1.87)$ & $1.41(1.10-1.80)$ & $1.41(1.10-1.80)$ \\
\hline \multicolumn{4}{|l|}{ Age (vs 18-34) } \\
\hline $35-39$ & $1.80(1.36-2.39)$ & $1.75(1.34-2.28)$ & $1.79(1.38-2.34)$ \\
\hline $40-44$ & $2.27(1.74-2.95)$ & $2.26(1.77-2.89)$ & $2.32(1.81-2.97)$ \\
\hline $45-49$ & $3.10(2.40-4.00)$ & $3.00(2.37-3.81)$ & $3.06(2.41-3.88)$ \\
\hline $50-54$ & $4.18(3.21-5.44)$ & $4.05(3.18-5.15)$ & $4.06(3.19-5.18)$ \\
\hline $55-59$ & $5.27(3.96-7.01)$ & $5.53(4.28-7.14)$ & $5.46(4.23-7.05)$ \\
\hline $60-64$ & $5.82(4.22-8.01)$ & $6.72(5.09-8.87)$ & $6.53(4.95-8.62)$ \\
\hline 65-69 & $9.98(7.33-13.60)$ & $10.42(7.88-13.76)$ & $9.92(7.50-13.11)$ \\
\hline 70-74 & $15.14(10.98-20.86)$ & 15.19 (11.34-20.34) & $14.26(10.64-19.11)$ \\
\hline $75-79$ & $25.28(17.57-36.37)$ & $25.14(18.19-34.74)$ & $23.21(16.77-32.11)$ \\
\hline $80+$ & $35.16(23.70-52.14)$ & $38.49(27.20-54.46)$ & $34.91(24.63-49.48)$ \\
\hline \multicolumn{4}{|l|}{ Injury factors } \\
\hline \multicolumn{4}{|l|}{ Etiology (vs MV/FL/Sp/Uk ${ }^{\mathrm{b}}$ ) } \\
\hline Violence & $1.11(0.90-1.37)$ & $1.13(0.94-1.37)$ & $1.12(0.93-1.35)$ \\
\hline Other & $1.20(0.97-1.47)$ & $1.18(0.98-1.42)$ & $1.18(0.98-1.42)$ \\
\hline \multicolumn{4}{|l|}{ SCI Level (vs non-cervical) } \\
\hline $\mathrm{C} 1-\mathrm{C} 4$ & $2.52(2.09-3.06)$ & $2.32(1.96-2.77)$ & $2.22(1.87-2.52)$ \\
\hline C5-C8 & $2.05(1.74-2.41)$ & $1.96(1.71-2.28)$ & $1.91(1.65-2.21)$ \\
\hline \multicolumn{4}{|l|}{ AIS/Frankel (vs D/E) } \\
\hline$A$ & $1.81(1.37-2.37)$ & $1.95(1.53-2.50)$ & $1.87(1.46-2.39)$ \\
\hline $\mathrm{B}$ & $1.30(0.94-1.80)$ & $1.55(1.16-2.06)$ & 1.49 (1.12-1.99) \\
\hline $\mathrm{C}$ & $1.08(0.78-1.49)$ & $1.18(0.88-1.57)$ & $1.13(0.85-1.51)$ \\
\hline \multicolumn{4}{|l|}{ AIS D*SCl level } \\
\hline $\mathrm{C} 1-\mathrm{C} 4+\mathrm{AIS} D$ & $0.34(0.22-0.52)$ & $0.41(0.28-0.61)$ & $0.41(0.28-0.61)$ \\
\hline C5-C8+AIS D & $0.61(0.43-0.88)$ & $0.68(0.49-0.93)$ & $0.68(0.49-0.93)$ \\
\hline \multicolumn{4}{|l|}{ Socioeconomic factors } \\
\hline \multicolumn{4}{|l|}{ Income (vs $\$ 75000+$ ) } \\
\hline$<\$ 25000$ & $2.31(1.76-3.02)$ & $2.10(1.67-2.64)$ & $1.82(1.44-2.30)$ \\
\hline$\$ 25000-\$ 74000$ & $1.61(1.23-2.12)$ & $1.50(1.19-1.88)$ & $1.38(1.10-1.74)$ \\
\hline \multicolumn{4}{|l|}{ Education (vs bachelors + ) } \\
\hline$<$ High school & $1.77(1.41-2.23)$ & $1.68(1.37-2.06)$ & $1.52(1.24-1.86)$ \\
\hline High school/associates & $1.44(1.20-1.72)$ & $1.40(1.19-1.64)$ & $1.28(1.09-1.50)$ \\
\hline \multicolumn{4}{|l|}{ Working hours (vs $30+\mathrm{h}$ ) } \\
\hline $\mathrm{Oh}$ & ND & ND & $1.67(1.36-2.05)$ \\
\hline $1-29 \mathrm{~h}$ & ND & ND & $1.37(1.01-1.86)$ \\
\hline
\end{tabular}

Stage I: Hosmer-Lemeshow Chi-square $=6.83, \mathrm{DF}=8, P=0.5550 ; \mathrm{C}=0.750$.

Stage II: Hosmer-Lemeshow Chi-square $=8.00, D F=8, P=0.4338 ; C=0.751$

adds ratios from previously published data (1036 deaths; 57947 person-years). Krause et al ${ }^{8}$

${ }^{b} \mathrm{MV} / \mathrm{Fl} / \mathrm{Sp} / \mathrm{Uk}=$ motor vehicle $\mathrm{crash} / \mathrm{fall} / \mathrm{sports} /$ unknown. 
income, the odd ratios of mortality were 2.10 for low income $(95 \%$ $\mathrm{CI}=1.67-2.64)$ and 1.50 for middle income $(95 \% \mathrm{CI}=1.19-1.88)$.

In stage 2, a significant effect was observed for working hours. Compared with those who worked $\geqslant 30 \mathrm{~h}$, those unemployed had 1.67 greater odds of mortality (95\% CI $=1.36-2.05)$, and those who worked $<30 \mathrm{~h}$ had 1.37 greater odds of mortality $(95 \%$ $\mathrm{CI}=1.01-1.86)$. Household income and years of education remained statistically significant, although the odds ratios decreased modestly.

\section{Life expectancy}

Life expectancy varied substantially based on the three SES indicators. For those with high cervical injuries (Table 3), the life expectancy of a 25-year-old with the most favorable characteristics (working, higher education and high income) was 95\% higher than for those with the least favorable characteristics (40.3 years compared with 20.7 years). The relative difference was even greater $(138 \%)$ for a 50 -year-old (20.2, 8.5). For those with non-cervical injuries (Table 4), the differences between favorable and unfavorable characteristics were of lower magnitude. The added life expectancy under favorable conditions was $60 \%$ for a 25 -year-old and $84 \%$ for a 50 -year-old.

\section{DISCUSSION}

Our results clearly indicate that poor socioeconomic circumstance, including gainful employment, is predictive of high mortality levels, above and beyond that attributable to the nature or severity of SCI. The unique contribution of this study was the addition of gainful employment as a socioeconomic predictor. Sadly, over 70\% were unemployed and over half were in the lowest income category.

How can employment and income be so highly related to mortality? One could question whether these findings reflect the 'healthy worker effect' (healthy people are more likely to work). ${ }^{16}$ However, these findings were obtained above and beyond the effect of severe disability (that is, SCI). Some research clearly suggests that employment is correlated with better overall health after SCI, ${ }^{17,18}$ but we cannot determine whether healthier people with SCI are more able to work or if the process of working and its related benefits lead to greater health.

The protective effect of household income appears to be relatively independent of the effects of education and employment. The odds of mortality associated with different levels of income dropped only $8-15 \%$ with the inclusion of employment as a predictor. Similar decreases were noted for education (10\%, 9\% decreases). Therefore, employment largely explained additional variation in mortality.

Two different conceptual models suggest that differences in income may not only affect access to care (a direct benefit of employment) but also intrinsic stressors ultimately leading to differences in health. ${ }^{9,19}$ The term allostatic load was developed to define the physiological consequences of prolonged exposure to repeated or chronic stress. ${ }^{20}$ It is measured typically by 10 biomarkers that in combination measure neuroendocrine response to stress. Individuals in lower socioeconomic strata have been demonstrated to have higher levels of allostatic load, as measured by these biomarkers, and poor health outcomes. ${ }^{21}$ In the context of the current study, the inherited stressors that result from low income and poor access to resources could account for the observed relationship between socioeconomic factors and mortality. This concept has been incorporated into a theoretical risk model of mortality after SCI. ${ }^{22}$

\section{Policy considerations}

These findings define the human cost of the policies and practices limiting educational, vocational and earning potential. There is no
Table 3 Life expectancy as a function of household income, years of education and current employment status for a white male with a C1-C4 SCI, ASIA A and injured in a motor vehicle crash

\begin{tabular}{|c|c|c|c|c|c|c|c|c|c|}
\hline \multirow{4}{*}{ Work hours } & \multicolumn{9}{|c|}{ Household income ${ }^{a}$} \\
\hline & & Low & & & Middle & & & High & \\
\hline & \multirow[b]{2}{*}{$<12$} & \multirow[b]{2}{*}{$12-15$} & \multirow[b]{2}{*}{$16+$} & \multicolumn{3}{|c|}{ Education $^{b}$} & \multirow[b]{2}{*}{$<12$} & \multirow[b]{2}{*}{$12-15$} & \multirow[b]{2}{*}{$16+$} \\
\hline & & & & $<12$ & $12-15$ & $16+$ & & & \\
\hline \multicolumn{10}{|l|}{ Age 25} \\
\hline 0 & 20.66 & 22.92 & 26.06 & 23.77 & 26.19 & 29.50 & 28.61 & 31.20 & 34.70 \\
\hline $1-29$ & 21.83 & 24.13 & 27.29 & 25.00 & 27.43 & 30.73 & 29.84 & 32.41 & 35.84 \\
\hline 0 & 7.27 & 29.57 & 32.61 & 30.42 & 32.74 & 35.77 & 34.96 & 37.29 & 40. \\
\hline
\end{tabular}

Age 50

$\begin{array}{llllllllll}0 & 8.47 & 9.79 & 11.69 & 10.30 & 11.78 & 13.88 & 13.30 & 14.99 & 17.36\end{array}$

$\begin{array}{llllllllll}1-29 & 9.08 & 10.42 & 12.34 & 10.94 & 12.42 & 14.51 & 13.94 & 15.62 & 17.96\end{array}$

$\begin{array}{llllllllll}>30 & 11.80 & 13.14 & 14.99 & 13.65 & 15.07 & 17.03 & 16.50 & 18.05 & 20.20\end{array}$

aFor income, low $=<\$ 25000$, middle $=\$ 25000-74999$ and high $=\$ 75000+$

bFor education, $<12=<$ high school, $12-15=$ high school/associates and $16+=$ bachelors + .

Table 4 Life expectancy as a function of household income, years of education and current employment status for a white male with a non-cervical SCI, ASIA A and injured in motor vehicle crash

\begin{tabular}{|c|c|c|c|c|c|c|c|c|c|}
\hline \multirow[t]{4}{*}{ Work hours } & \multicolumn{9}{|c|}{ Household income ${ }^{a}$} \\
\hline & \multirow[b]{3}{*}{$<12$} & \multicolumn{2}{|l|}{ Low } & \multirow{2}{*}{\multicolumn{3}{|c|}{$\begin{array}{c}\text { Middle } \\
\text { Education }^{b}\end{array}$}} & \multirow[b]{3}{*}{$<12$} & \multicolumn{2}{|l|}{ High } \\
\hline & & \multirow[b]{2}{*}{$12-15$} & \multirow[b]{2}{*}{$16+$} & & & & & \multirow[b]{2}{*}{$12-15$} & \multirow[b]{2}{*}{$16+$} \\
\hline & & & & $<12$ & $12-15$ & $16+$ & & & \\
\hline \multicolumn{10}{|l|}{ Age 25} \\
\hline 0 & 31.18 & 33.65 & 37.40 & 34.83 & 37.55 & 41.13 & 40.18 & 42.87 & 46.17 \\
\hline $1-29$ & 32.39 & 35.00 & 38.49 & 35.97 & 38.64 & 42.11 & 41.19 & 43.80 & 46.99 \\
\hline $30>$ & 37.27 & 39.60 & 42.66 & 40.45 & 42.79 & 45.81 & 45.01 & 47.26 & 49.97 \\
\hline \multicolumn{10}{|l|}{ Age 50} \\
\hline 0 & 14.98 & 16.78 & 19.27 & 17.45 & 19.37 & 21.96 & 21.27 & 23.24 & 25.68 \\
\hline $1-29$ & 15.60 & 17.38 & 19.83 & 18.05 & 19.93 & 22.47 & 21.80 & 23.72 & 26.10 \\
\hline $30>$ & 18.04 & 19.67 & 21.92 & 20.28 & 22.02 & 24.33 & 23.72 & 25.47 & 27.61 \\
\hline
\end{tabular}

a For income, low $=<\$ 25000$; middle $=\$ 25000-74999$ and high $=\$ 75000+$

bFor education, $<12=<$ high school, $12-15=$ high school/associates and $16+=$ bachelors + .

universal access to health care in the United States, so economic factors likely affect mortality in a number of ways, including differential access to health-care services. Furthermore, federally funded health-care programs in the United States provide disincentives to employment such that an individual may jeopardize health benefits by working and earnings. These policies systematically limit employment, particularly full-time employment, and contribute to a pattern of poverty, which may, in turn, limit longevity. New legislation may break the cycle of poverty by removing disincentives to health care and employment, thereby also removing barriers to longevity.

\section{Methodological considerations}

There are considerations that aid in the interpretation of the findings but do not undermine the study validity. First, the SCIMSs are not 
population-based. However, the data were collected from several regional centers, which are generally representative of the distribution of the population in the United States. Second, the findings do not apply to those who are ventilator-dependent, $<1$ year post injury, or have non-traumatic SCI, as these were exclusion criteria. Participants averaged 8.2 years post injury at the time of enrollment, so the findings are more representative of those who have survived the first few years post injury. Third, the current findings may be conservative, and the actual relationship between socioeconomic factors of mortality may be greater than suggested by the current findings. Socioeconomic data were self-reported, and inaccurate reporting would have led to smaller effect sizes. Also, there is an artificial ceiling on income level at $>\$ 75000$ per year, so even higher levels of income may be associated with a further decrease in mortality. In terms of capturing deceased cases, the Security Death Index was found to have 92.4\% sensitivity among deceased persons with SCI, so some deaths likely occurred but went unreported. ${ }^{10}$ This also may have led to a smaller effect size for any given predictor, yet a potential small overestimation of life expectancy with any given characteristics. Lastly, socioeconomic factors may change over time and predicting life expectancy shortly after SCI onset may be difficult, particularly as related to gainful employment. Life expectancy estimates likely become more stable as the individual's life situation and SES stabilize in the years after SCI onset.

\section{Future research}

We need to identify the mechanisms by which SES is related to mortality, including access to health care, resources and psychological and biological measures that may covary with SES. Identification of systematic biases in the Security Death Index would help evaluate the quality of mortality analyses. More sophisticated policy studies are needed to more directly determine the effects of financial disincentives to employment on mortality rates. Lastly, we need to evaluate the extent to which socioeconomic factors are differentially related to causes of death.

\section{CONCLUSION}

Gainful employment is inversely related with risk of mortality, above and beyond the effects of factors demonstrated in previous research including demographic, injury-related and other socioeconomic factors (education and income). These findings challenge the notion that current levels of mortality are the inevitable consequence of SCI.

\section{DATA ARCHIVING}

There were no data to deposit.

\section{CONFLICT OF INTEREST}

The authors declare no conflict of interest.

\section{ACKNOWLEDGEMENTS}

The contents of this publication were developed under grants from the Department of Education, NIDRR grant numbers H133N060009 and H133B090005. However, those contents do not necessarily represent the policy of the Department of Education, and you should not assume endorsement by the Federal Government. We would like to thank the following persons who contributed to the work reported in the manuscript: Richard Aust, Josh Acuna, Dr Yue Cao, Jennifer Coker, Emily Johnson and Karla Reed.

1 DeVivo MJ, Krause JS, Lammertse DP. Recent trends in mortality and causes of death among persons with spinal cord injury. Arch Phys Med Rehabil 1999; 80: 1411-1419.

2 Shavelle RM, DeVivo MJ, Strauss DJ, Paculdo DR, Lammertse DP, Day SM. Long-term survival of persons ventilator dependent after spinal cord injury. J Spinal Cord Med 2006; 29: 511-519.

3 Torssander J, Erikson R. Stratification and mortality - a comparison of education, class, status, and income. Eur Sociol Rev 2010; 26: 465-474.

4 Stringhini S, Sabia S, Shipley M, Brunner E, Nabi H, Kivimaki M et al. Association of socioeconomic position with health behaviors and mortality. JAMA 2010; 303 1159-1166.

5 Rask K, O'Malley E, Druss B. Impact of socioeconomic, behavioral and clinical risk factors on mortality. J Public Health 2009; 31: 231-238.

6 Krause JS, DeVivo MJ, Jackson AB. Health status, community integration, and economic risk factors for mortality after spinal cord injury. Arch Phys Med Rehabil 2004; 85: 1764-1773.

7 Strauss D, DeVivo M, Shavelle R, Brooks J, Paculdo D. Economic factors and longevity in spinal cord injury: a reappraisal. Arch Phys Med Rehabil 2008; 89: 572-574.

8 Krause JS, Saunders LL, DeVivo MJ. Income and risk of mortality after spinal cord injury. Arch Phys Med Rehabil 2011; 92: 339-345.

9 Krause JS, Saunders LL. Life expectancy estimates in the life care plan: Accounting for economic factors. J Life Care Plan 2010; 9: 15-28.

10 DeVivo MJ, Stover SL, Black KJ. Prognostic factors for 12-year survival after spina cord injury. Arch Phys Med Rehabil 1992; 73: 156-162.

11 Frankel HL, Hancock DO, Hyslop G, Melzak J, Michaelis LS, Ungar GH et al. The value of postural reduction in the initial management of closed injuries of the spine with paraplegia and tetraplegia. Paraplegia 1969; 7: 179-192.

12 Maynard FM, Bracken MB, Creasey G, Ditunno JF, Donovan WH, Ducker TB et al. International standards for neurological and functional classification of spinal cord injury. American Spinal Injury Association. Spinal Cord 1997; 35: 266-274.

13 Krause JS, Kewman D, DeVivo MJ, Maynard F, Coker J, Roach MJ et al. Employment after spinal cord injury: An analysis of cases from the Model Spinal Cord Injury Systems. Arch Phys Med Rehabil 1999; 80: 1492-1500.

14 Strauss D, Shavelle R, DeVivo MJ, Day S. An analytic method for longitudinal mortality studies. J Insur Med 2000; 32: 217-225.

15 Hosmer DW, Lemeshow S. Applied logistic regression, 2nd ed. John Wiley and Sons: New York, NY, 2000

16 Monson RR. Observations on the healthy worker effect. J Occup Med 1986; 28 425-433.

17 Meade MA, Forchheimer M, Krause JS, Charlifue S. The influence of secondary conditions on job acquisition and retention in adults with spinal cord injury. Arch Phys Med Rehabil 2011; 92: 425-432.

18 Lidal IB, Huynh TK, Biering-Sorensen F. Return to work following spinal cord injury: a review. Disabil Rehabil 2007; 29: 1341-1375.

19 Krause JS. Secondary conditions and spinal cord injury: A model for prediction and prevention. Top Spinal Cord Inj Rehabil 1996; 2: 217-227.

20 McEwen BS. Stress, adaptation, and disease. Allostasis and allostatic load. Ann N Y Acad Sci 1998; 840: 33-44

21 Seeman T, Merkin SS, Crimmins E, Koretz B, Charette S, Karlamangla A. Education, income and ethnic differences in cumulative biological risk profiles in a national sample of US adults: NHANES III (1988-1994). Soc Sci Med 2008; 66: 72-87.

22 Krause JS, Zhai Y, Saunders LL, Carter RE. Risk of mortality after spinal cord injury: an 8-year prospective study. Arch Phys Med Rehabil 2009; 90: 1708-1715. 